\title{
Pengenalan Citra Bunga Menggunakan Segmentasi Otsu Threshold dan Naïve Bayes
}

\author{
Perani Rosyani ${ }^{1}$, Oke Hariansyah ${ }^{2}$ \\ Universitas Pamulang \\ e-mail: 1'dosen00837@unpam.ac.id, 2dosen00840@unpam.ac.id \\ Diajukan: 10 Mei 2020; Direvisi: 9 Juni 2020; Diterima: 30 Juni 2020
}

\begin{abstract}
Abstrak
Bunga merupakan salah satu bagian tumbuhan yang mempunyai warna mencolok dibanding batang kayu dan daun. Bunga merupakan salah satu fitur penting dalam proses pengenalan objek. Proses pengenalan objek pada segmentasi digital sangat penting untuk memisahkan antara background dan foreground dari sebuah citra. Hal ini bertujuan untuk mendapatkan fitur-fitur yang dibutuhkan. Citra bunga pada penelitian ini memiliki kompleksitas gambar cukup sulit karena ada daun dan batang pohon di sekeliling gambar bunga tersebut. Oleh Karena itu, dalam penelitian ini segmentasi yang diusulkan menggunakan Otsu Threshold sebagai metode untuk memisahkan foreground dan background. Proses segmentasi sangat menentukan untuk mendapatkan fitur bentuk berupa area, eccentricity, dan perimeter. Hasil kalkulasi dari fitur-fitur tersebut akan diklasifikasi menggunakan algoritma Nä̈ve Bayes dengan menggunakan 120 citra bunga dari dataset 17 flower. Dataset tersebut akan dibagi menjadi data tes dan data training, dan menggunakan cross validasi $(k=10)$. Hasil dari klasifikasi menggunakan Nä̈ve Bayes mendapatkan tingkat akurasi yang lebih tinggi sebesar $99.168 \%$ dengan relative absolute error sebesar 8.0937\% dibandingkan dengan penelitian sebelumnya sebesar $83.83 \%$.
\end{abstract}

Kata kunci: Pengenalan bunga, Otsu Threshold, Nä̈ve Bayes, Klasifikasi.

\begin{abstract}
Flower are one part of the plant that has striking color compared to tree trunks and leaves. Flower is one of the important features in the object recognition process. In the process of introducing digital segmentation objects, it is very important to separate the background and foreground from an image. It aims to get the features needed. Image of flowers in this study has a complexity of images is quite difficult because there are leaves and tree trunks around the flower image. Therefore, in this study the proposed segmentation uses the Otsu Threshold as a method for separating the foreground and background. The segmentation process is crucial to get the shape features in the from area, eccentricity, and perimeters. The results of the calculations of these features will be classified using the naïve Bayes algorithm by using 120 flower images of 17 flower datasets. The dataset will be divided into test data and training data and use cross-validation $(k=10)$. The results of the classification using Naïve Bayes get a higher accuracy rate of $99.168 \%$ with a relative absolute error of $8.094 \%$ compared with previous studies of $83.83 \%$.
\end{abstract}

Keywords: Recognition, Flower, Otsu Threshold, Naïve Bayes, Classification.

\section{Pendahuluan}

Pengenalan citra digital banyak mendapatkan perhatian dalam beberapa tahun terakhir. Beberapa bidang telah menerapkan pengenalan citra digital di berbagai bidang dan objek, seperti untuk pengenalan citra wajah [1], pengenalan bunga anggrek [2], mengenali pelat kendaraan[3], bahkan di bidang pertanian untuk menentukan kualitas cabai yang bagus [4]. Proses pengenalan objek ini memiliki tahapan-tahapan seperti preprocessing yang harus dilalui, yaitu dengan melakukan segmentasi untuk mendapatkan fitur dari objek tersebut. Objek di dalam penelitian ini adalah bunga dengan kondisi background yang cukup kompleks. Meskipun daun sangat penting di dalam proses pengenalan tanaman [5], bunga juga termasuk bagian yang mendukung untuk proses tersebut. Pengenalan bunga merupakan proses yang menantang karena beberapa fitur harus dikombinasikan [6], termasuk tekstur warna [7], matriks co-accurance tingkat abu-abu, dan filter gabor. Kombinasi beberapa fitur ini untuk menjaga tingkat akurasi tetap tinggi dalam pengenalan objek. Objek yang kami ambil dalam proses pengenalan objek adalah bunga karena bunga merupakan salah satu bagian tumbuhan yang mempunyai warna mencolok dibanding batang dan daun [8]. 
Dalam penelitian ini, kami menggunakan segmentasi dari Otsu Threshold yang dinilai mudah di dalam proses mendapatkan ciri dari suatu gambar [9]. Segmentasi citra ini bertujuan untuk mendapatkan ekstraksi ciri bentuk [10] dari bunga yaitu area, perimeter, dan eccentricity. Ciri bentuk ini didapat setelah melewati penambahan beberapa operasi untuk menghilangkan noise di dalam citra seperti operasi filling holes, filtering, serta area open. Hal ini merupakan bentuk optimalisasi setelah proses segmentasi menggunakan Otsu Threshold. Dalam penelitian ini menggunakan Naïve Bayes untuk mengklasifikasi hasil ekstraksi fitur bentuk untuk mengenali objek bunga. Pada penelitian yang dilakukan oleh Bima, dkk menggunakan Naïve Bayes Classifier dengan Eigenface untuk memprediksi tingkat akurasi pengenalan wajah[11], di dalam penelitiannya berhasil meningkatkan tingkat akurasi menjadi $89.5 \%$. sedangkan untuk sistem prediksi menggunakan Naïve Bayes pada penelitian Azman didapat tingkat akurasi sebesar 83.83\% [12]

Naïve Bayes Classifier merupakan salah satu metode klasifikasi yang dapat mengenali objek dengan dataset minimum [13]. Hal ini sangat menguntungkan karena pada penelitian ini kami menggunakan 120 dataset dari 17 flower dengan 2 class yang berbeda. Dataset tersebut akan dibagi menjadi data tes dan data training dan menggunakan cross validasi $(\mathrm{k}=10)$. Tujuan dari penelitian ini adalah untuk mendapatkan tingkat akurasi yang lebih baik daripada penelitian sebelumnya pada proses pengenalan objek, hal ini didukung dengan proses segmentasi citra menggunakan Otsu Threshold dan penambahan operasi-operasi citra lainya untuk membersihkan noise, sehingga objek yang dihasilkan bersih tanpa noise.

\section{Metode Penelitian}

Metode yang diusulkan untuk klasifikasi citra bunga memiliki 2 fase yaitu fase pelatihan dan fase pengujian. Fase pelatihan bertujuan untuk membangun model berdasarkan subset gambar yang disebut citra latih [14]. Pertama, gambar tersebut tersegmentasi dengan metode Otsu Threshold dan fitur diekstraksi. Kemudian, fitur akan dihitung dan digunakan untuk pengklasifikasian menggunakan Naïve Bayes.

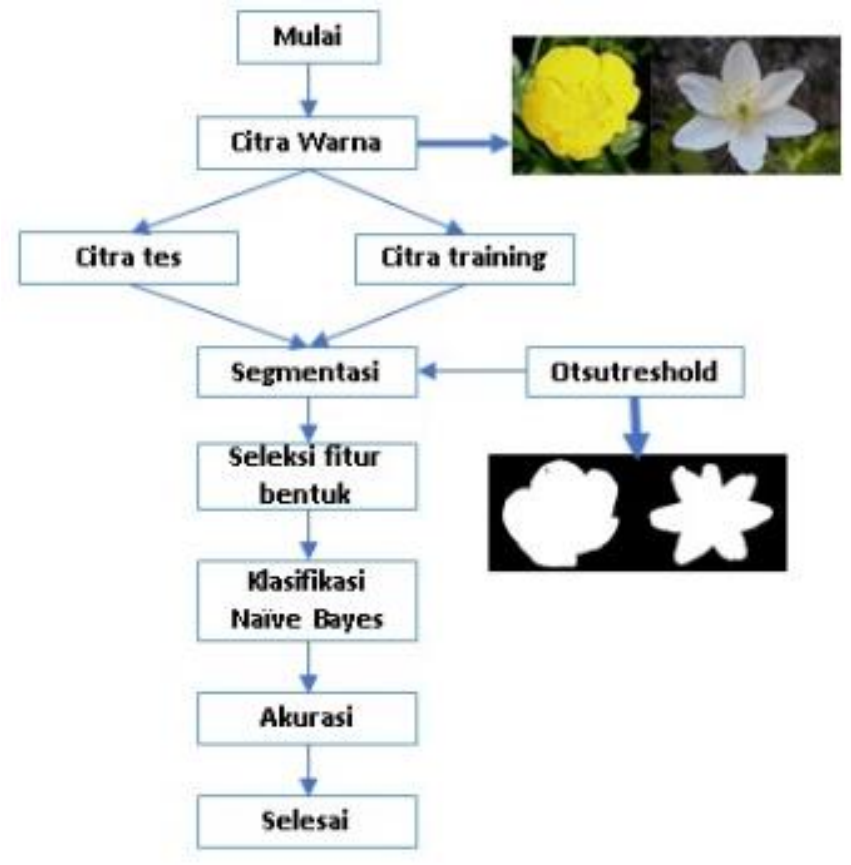

Gambar 1. Metode penelitian.

Berikut penjelasan Gambar 1 untuk metode penelitian yang kami usulkan:

1. Pertama adalah pemilihan citra dari data set 17 flower di mana dataset tersebut mengambil 2 jenis bunga dengan bunga 1 berwarna kuning dan bunga 2 berwarna putih sebanyak 120 citra. Citra tersebut memiliki kompleksitas dari sisi background, karena antara background dan foreground harus dipisahkan untuk mendapatkan objek utuh sehingga dapat dihitung fitur bentuk yang dihasilkan.

2. 120 citra warna yang terpilih akan dibagi menjadi citra latih sebanyak 100 citra dan citra tes sebanyak 20 citra. 
3. Setiap citra tes dan citra latih akan disegmentasi menggunakan metode Otsu Threshold, dan melalui operasi-operasi untuk membersihkan noise yang ada, seperti medfilte, opening, closing, filling holes, dan openarea

4. Seleksi fitur bentuk, di dalam tahapan ini hasil segmentasi citra Otsu Threshold akan dihitung nilai perimeter, eccentricity, dan areanya.

5. Klasifikasi Naïve Bayes, hasil kalkulasi fitur bentuk akan diklasifikasi menggunakan metode Naïve Bayes dengan tujuan untuk mendapatkan tingkat akurasi dari pengenalan citra bunga ini.

6. Setelah fitur dihitung menggunakan algoritma Naïve Bayes kita akan dapatkan nilai akurasi dari perhitungan tersebut.

\subsection{Image Data Colletion}

Dataset yang digunakan menggunakan dataset dari 17 flower sebanyak 120 gambar dengan 2 class bunga. Masing-masing dengan 60 gambar yang akan dibagi menjadi 90\% citra latih dengan total 50 gambar dan $10 \%$ citra uji dengan total 10 gambar.

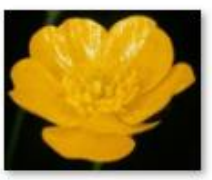

image_1170.jpg

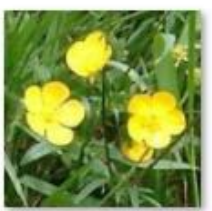

image_1182.jpg

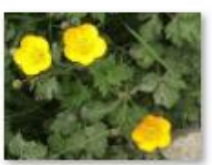

image_1194.jpg

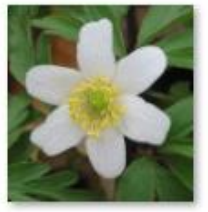

image_1206.jpg

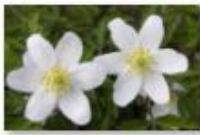

image_1218.jpg

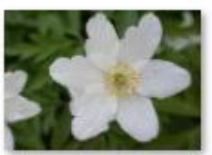

image_1230.jpg

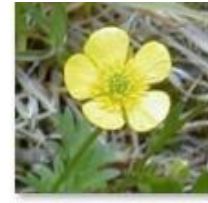

image_1171.jpg

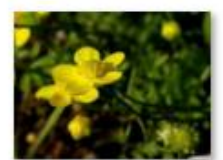

image_1183.jpg

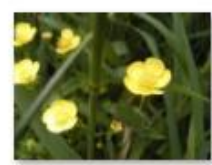

image_1195.jpg

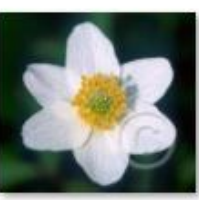

image_1207.jpg

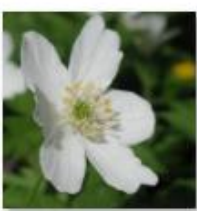

image_1219.jpg

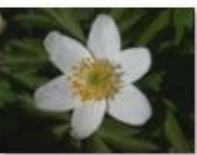

image_1231.jpg

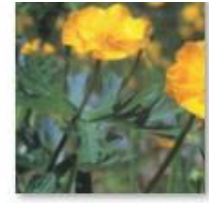

image_1172.jpg

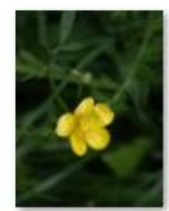

image_1184.jpg

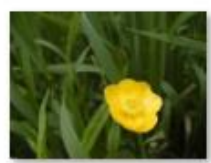

image_1196.jpg

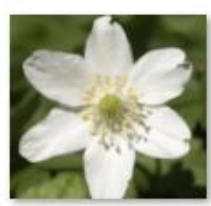

image_1208.jpg

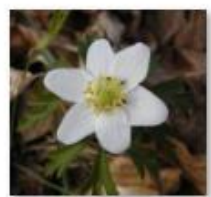

image_1220.jpg

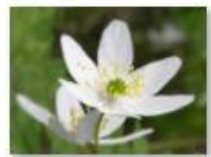

image_1232.jpg

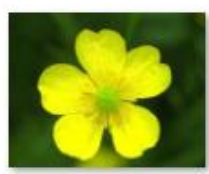

image_1173.jpg

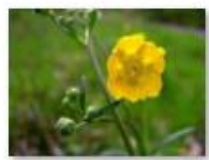

image_1185.jpg

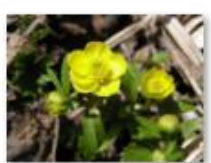

image_1197.jpg

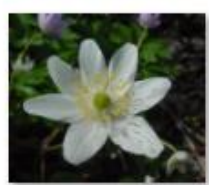

image_1209.jpg

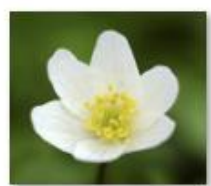

image_1221.jpg

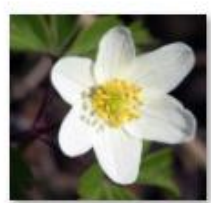

image_1233.jpg

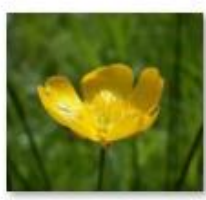

image_1174.jpg

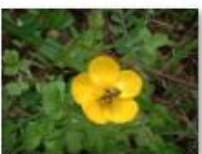

image_1186.jpg

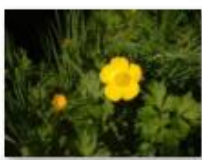

image_1198.jpg

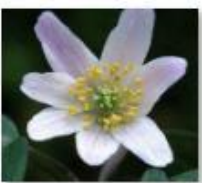

image_1210.jpg

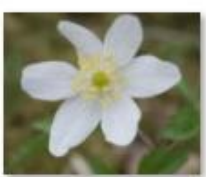

image_1222.jpg

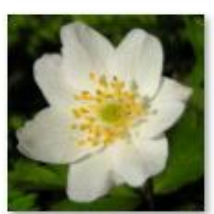

image_1234.jpg

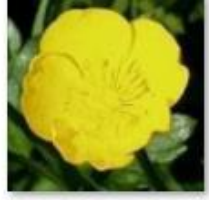

image_1175.jpg

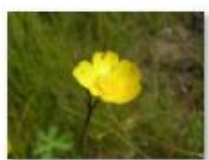

image_1187.jpg

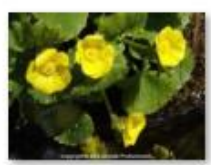

image_1199.jpg

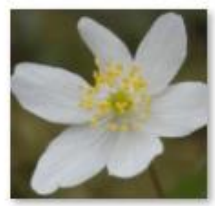

image_1211.jpg

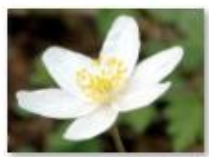

image_1223.jpg

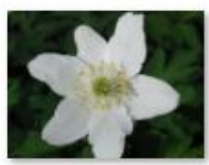

image_1235.jpg

Gambar 2. Contoh dataset. 


\subsection{Image Data Pre-processing}

Dalam tahapan preprocessing, langkah yang harus dilewati untuk mendapatkan bentuk yang sempurna, kita memerlukan ekstraksi fitur pada gambar bunga ini. Tahapan tersebut dapat kita lihat pada Gambar 3. Pada keterangan gambar tersebut langkah pertama adalah konversi citra true color menjadi citra grayscale. Dari citra grayscale kita konversi menjadi citra incomplement, dan langkah selanjutnya mengubahnya menjadi citra hitam putih. Langkah selanjutnya mengubah nilai matriks yang ada di dalam citra hitam putih menjadi kebalikannya, nilai 0 pada matriks citra tersebut diubah menjadi angka 1 , begitu juga sebaliknya, hal ini bertujuan untuk mendapatkan region yang jelas seperti pada poin e. Langkah selanjutnya pada f merupakan citra hasil pembersihan noise melalui operasi-operasi citra seperti filling holes, erosi, opening, closing, dan openarea.
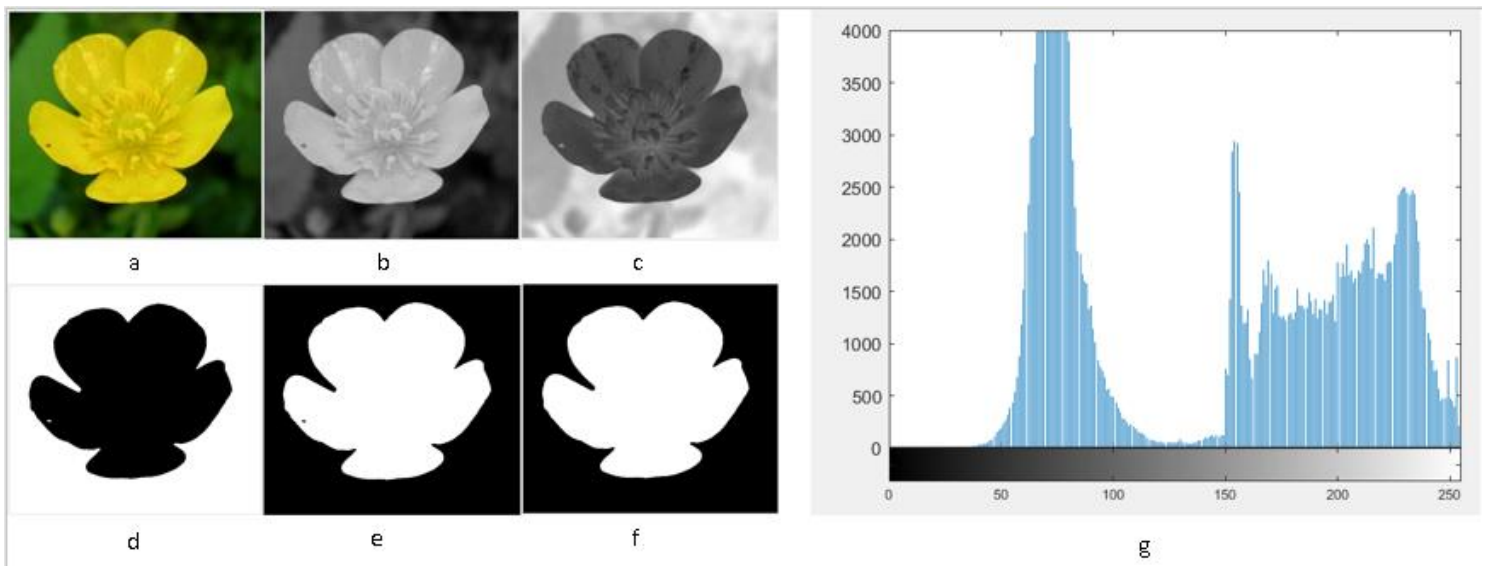

Gambar 3. Proses pengambilan bentuk. a. citra asli; b. citra grayscale; c. citra incomplement; d. citra biner; e. kebalikan citra biner; f. citra hasil penambahan operasi; g. grafik dari citra biner.

\subsection{Citra Training}

Citra training berisi nilai fitur bentuk perimeter, area, serta eccentricity. Citra training terdiri dari 100 gambar dengan 2 jenis bunga yang berbeda.

\subsection{Naïve Bayes}

Naïve Bayes adalah metode pengklasifikasi yang diperkenalkan oleh Thomas Bayes. Metode ini mempelajari data dan memprediksi kelas yang memiliki probabilitas [11].

$$
(A \mid B)=\frac{P(B \mid A) * P(A)}{P(B)}
$$

Di mana $P(A)$ dan $P(B)$ adalah probabilitas dari pengamatan $A$ dan $B$ [15]. $P(B \mid A)$ adalah untuk mengamati peristiwa $B$ yang diberikan adalah benar.

Persamaan Naïve Bayes diwakili oleh $P(A \mid B)$, $A$ adalah a vector input yang memiliki fitur dan $B$ adalah label kelas [16]. Berdasarkan pada informasi dari data pelatihan, untuk setiap kombinasi dan $B$, probabilitas akhir $P(B \mid A)$ model harus dilatih. Dengan model itu, pengujian data $A$ dapat dideklarasikan dengan pencarian nilai $B$ dengan memaksimalkan nilai $P\left(A^{\prime} \mid B^{\prime}\right)$. Lalu untuk klasifikasi, rumus Naïve Bayes dapat dinyatakan sebagai persamaan.

$$
P(B \mid A)=\frac{P(Y) \prod_{i=1}^{q} P\left(A_{i} \mid B\right)}{P(A)}
$$

Di mana $P(B \mid A)$ adalah probabilitas untuk vector adikelas $Y . P(Y)$ adalah probabilitas awal kelas

$Y$.

$\prod_{i=1}^{q} P\left(A_{i} \mid B\right)$ adalah probabilitas independen kelas $B$ dari semua fitur dalam vector $A$. nilai $P(A)$ selalu merupakan nilai tetap demikian dalam perhitungan selanjutnya kita perlu menghitung (B) $\prod_{i=1}^{q} P\left(A_{i} \mid B\right)$ untuk memilih nilai maksimum dari kelas yang dipilih sebagai hasil prediksi dari probabilitas independent. Selain itu probabilitas independen $\prod_{i=1}^{q} P\left(A_{i} \mid B\right)$ adalah pengaruh semua fitur dari data untuk setiap kelas $B$. 


$$
P(x=v \mid c)=\frac{1}{\sqrt{2 \pi} \sigma^{2}} e^{-\frac{(v-\mu)^{2}}{2 \sigma^{2}}}
$$

\section{Hasil dan Pembahasan}

Hasil dari penelitian ini untuk mendapatkan tingkat akurasi terbaik dari penelitian sebelumnya dengan menerapkan algoritma Naïve Bayes sebagai metode klasifikasi pada proses pengenalan citra bunga. Pengolahan citra menggunakan software Matlab dan pengklasifikasian menggunakan Weka tools dengan menggunakan algoritma Naïve Bayes.

\subsection{Variable Naïve Bayes}

Variable di dalam perhitungan Naïve Bayes menggunakan fitur bentuk dari perimeter, area, dan eccentricity. Bisa kita lihat pada Tabel 1, hasil statistik dari 2 jenis bunga yang berbeda. Bunga 1 mempunyai mean dari variable perimeter sebesar 964,54 sedangkan Bunga 2 sebesar 1227,31. Hal ini membuktikan perimeter Bunga 2 lebih besar daripada Bunga 1, hal itu dapat terlihat dari gambar Bunga 1 dan Bunga 2. Dari variable area pun terlihat jelas, nilai rata-rata variable area pada Bunga 2 lebih besar yaitu 122815,29 dibandingkan dengan variable area pada Bunga 1 yang memiliki rata-rata variable area sebesar 91845,68.

Tabel 1. Hasil statistic.

\begin{tabular}{lllllll}
\hline \multicolumn{1}{c}{ Class } & \multicolumn{1}{c}{ Bunga 1 } & & \multicolumn{2}{c}{ Bunga 2 } \\
\hline Atrribut & \multicolumn{1}{c}{ Mean } & Std. Dev & Precision & Mean & Std. Dev & Precision \\
\hline Perimeter & 964.5444 & 586.1713 & 17.8951 & 1227.3037 & 478.6421 & 17.8951 \\
\hline Area & 91845.6853 & 77201.5471 & 2481.1171 & 122815.2973 & 69753.5237 & 2481.1171 \\
\hline Eccentricity & 0.5519 & 0.2094 & 0.009 & 0.5398 & 0.2019 & 0.009 \\
\hline
\end{tabular}

\subsection{Indikator Evaluasi}

Kita menggunakan 3 indikator evaluasi: recall rate $(\mathrm{R})$, precision rate $(\mathrm{P})$, dan $\mathrm{F}$ value $(\mathrm{F})$ sebagai bahan analisis untuk menentukan tingkat akurasi yang baik.

$$
\begin{gathered}
R=\frac{\text { objek dikenali dengan benar }}{\text { jumlah semua objek didalam gambar }} \times 100 \% \\
P=\frac{\text { objek dikenali dengan benar }}{\text { jumlah semua objek didalam dataset }} \times 100 \% \\
P=\frac{2 x R \times P}{R+P} \times 100 \%
\end{gathered}
$$

Dari hasil perhitungan dengan indikator recall $(\mathrm{R})$ pada Bunga 1, kita dapatkan hasil akurasi hingga $100 \%$ dan $98.3 \%$ pada Bunga 2. Untuk indikator precision rate $(\mathrm{P})$ pada Bunga 1 sebesar $98.4 \%$ dan 100\% pada Bunga 2. Untuk indikator $\mathrm{F}$ value (F) pada Bunga 1 dan Bunga 2 sama-sama mempunyai nilai yang sama yaitu $99.2 \%$. Hal ini dapat dilihat dari Tabel 2 di bawah ini.

Tabel 2. Hasil evaluasi.

\begin{tabular}{ccc}
\hline & Bunga 1 & Bunga 2 \\
\hline TP Rate & $100 \%$ & $98.3 \%$ \\
\hline FP Rate & $1.7 \%$ & $0 \%$ \\
\hline $\mathbf{R}$ & $100 \%$ & $98.3 \%$ \\
\hline $\mathbf{P}$ & $98.4 \%$ & $100 \%$ \\
\hline F & $99.2 \%$ & $99.2 \%$ \\
\hline
\end{tabular}

Dari hasil uji yang dilakukan dengan menggunakan 120 gambar, dengan menggunakan cross validasi $(\mathrm{k}=10)$ dapat kita simpulkan bahwa tingkat akurasi yang didapat dengan menggunakan algoritma Naïve Bayes sebesar $99.1667 \%$ dengan nilai relative absolute error sebesar $8.0937 \%$. Fitur bentuk yang baik dari hasil segmentasi dapat kita lihat dari sample pada Gambar 4. Kita bisa lihat bentuknya yang sempurna tanpa noise, hal ini sangat mempengaruhi hasil klasifikasi dengan Naïve Bayes, karena di dalam penelitian sebelumnya dengan klasifikasi yang sama hanya mendapatkan tingkat akurasi sebesar $89.5 \%$ [11]. 

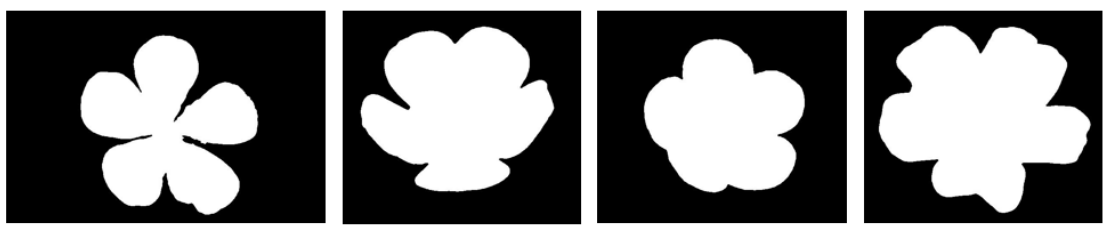

Bunga 1
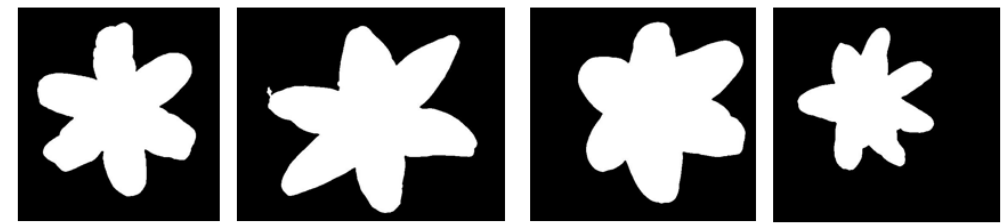

Bunga 2

Gambar 4. Contoh gambar hasil segmentasi hasil Otsu Threshold.

\section{Kesimpulan}

Dari hasil penelitian kita bisa ambil kesimpulan sebagai berikut:

1. Berdasarkan penelitian dengan menggunakan 120 citra bunga, maka nilai False Positive (FP) pada Bunga 1 sebesar 1,7\% sedangkan pada Bunga 2 sebesar $0 \%$.

2. Segmentasi menggunakan Otsu Threshold pada penelitian ini dinilai dapat membersihkan noise lebih baik dan meningkatkan tingkat akurasi di dalam proses klasifikasi menggunakan Naïve Bayes sebesar 99,17\% dengan tingkat absolute error sebesar 8,0937\%.

\section{Daftar Pustaka}

[1] P. Rosyani, "Pengenalan Wajah Menggunakan Metode Principal Component Analysis (PCA) dan Canberra Distance," J. Inform. Univ. Pamulang, vol. 2, no. 2, p. 118, 2017.

[2] D. H. Apriyanti, A. M. Arymurthy, and L. T. Handoko, "Identification of orchid species using contentbased flower image retrieval," Proceeding-2013 Int. Conf. Comput. Control. Informatics Its Appl. “Recent Challenges Comput. Control Informatics”, IC3INA 2013, no. March 2015, pp. 53-57, 2013.

[3] F. Tanoto, E. Wibowo, F. Lutan, and A. Dharma, "Pengenalan Plat Kendaraan Bermotor Dengan Menggunakan,” J. MATRIK, vol. 19, no. 1, pp. 27-36, 2019.

[4] F. Ugm, "Klasifikasi Varietas Cabai Berdasarkan Morfologi Daun Menggunakan Backpropagation Neural Network," vol. 10, no. 2, pp. 161-172, 2016.

[5] S. Bertrand, R. Ben Ameur, G. Cerutti, D. Coquin, L. Valet, and L. Tougne, "Bark and leaf fusion systems to improve automatic tree species recognition," Ecol. Inform., vol. 46, no. 2017, pp. 57-73, 2018.

[6] D. S. Guru, Y. H. Sharath Kumar, and S. Manjunath, "Textural features in flower classification," Math. Comput. Model., vol. 54, no. 3-4, pp. 1030-1036, 2011.

[7] S. Inthiyaz, B. T. P. Madhav, and P. V. V. Kishore, "Flower image segmentation with PCA fused colored covariance and gabor texture features based level sets," Ain Shams Eng. J., vol. 9, no. 4, pp. 3277-3291, 2018.

[8] P. Rosyani, M. Taufik, A. A. Waskita, and D. H. Apriyanti, "Comparison of color model for flower recognition,” 2018 3rd Int. Conf. Inf. Technol. Inf. Syst. Electr. Eng., pp. 10-14, 2019.

[9] F. Muwardi and A. Fadlil, "Sistem Pengenalan Bunga Berbasis Pengolahan Citra dan Pengklasifikasi Jarak," J. Ilm. Tek. Elektro Komput. dan Inform., vol. 3, no. 2, p. 124, 2018.

[10] I. R. G. A. Sugiartha, M. Sudarma, and I. M. O. Widyantara, "Ekstraksi Fitur Warna, Tekstur dan Bentuk untuk Clustered-Based Retrieval of Images ( CLUE )," Teknol. Elektro, vol. 16, no. 1, pp. 8590, 2017.

[11] E. B. Putranto, P. A. Situmorang, and A. S. Girsang, "Face recognition using eigenface with naive Bayes," Proc.-11th 2016 Int. Conf. Knowledge, Inf. Creat. Support Syst. KICSS 2016, no. 4, pp. 912, 2017.

[12] M. A. Maricar and Dian Pramana, "Perbandingan Akurasi Naïve Bayes dan K-Nearest Neighbor pada Klasifikasi untuk Meramalkan Status Pekerjaan Alumni ITB STIKOM Bali,” J. Sist. dan Inform., vol. 14, no. 1, pp. 16-22, 2019.

[13] S. K. Bhakre and A. Bang, "Emotion recognition on the basis of audio signal using Naive Bayes 
classifier," 2016 Int. Conf. Adv. Comput. Commun. Informatics, ICACCI 2016, pp. 2363-2367, 2016.

[14] A. B. Mabrouk, A. Najjar, and E. Zagrouba, "Image flower recognition based on a new method for color feature extraction," VISAPP 2014-Proc. 9th Int. Conf. Comput. Vis. Theory Appl., vol. 2, 2014.

[15] N. Ben Amor, S. Benferhat, and Z. Elouedi, "Naive Bayes vs decision trees in intrusion detection systems," Proc. ACM Symp. Appl. Comput., vol. 1, pp. 420-424, 2004.

[16] A. Kelemen, H. Zhou, P. Lawhead, and Y. Liang, "Naive Bayesian Classifier for Microarray Data," Proc. Int. Jt. Conf. Neural Networks, vol. 3, pp. 1769-1773, 2003. 